\title{
Nationwide Results of COVID-19 Contact Tracing in South Korea: Individual Participant Data From an Epidemiological Survey
}

Seung Won Lee ${ }^{1^{*}}, \mathrm{MD}$, PhD; Woon Tak Yuh ${ }^{2 *}, \mathrm{MD}$; Jee Myung Yang ${ }^{3 *}, \mathrm{MD}, \mathrm{PhD}$; Yoon-Sik Cho ${ }^{1}$, PhD; In Kyung $\mathrm{Yoo}^{4}, \mathrm{MD}, \mathrm{PhD}$; Hyun Yong $\mathrm{Koh}^{5}, \mathrm{MD}, \mathrm{PhD}$; Dominic Marshall ${ }^{6}, \mathrm{MD}$; Donghwan $\mathrm{Oh}^{7}$, MD; Eun Kyo $\mathrm{Ha}^{8}, \mathrm{MD}$; Man Yong $\mathrm{Han}^{9}$, MD; Dong Keon Yon ${ }^{9,10}$, MD

${ }^{1}$ Department of Data Science, Sejong University College of Software Convergence, Seoul, Republic of Korea

${ }^{2}$ Department of Neurosurgery, Seoul National University Hospital, Seoul, Republic of Korea

${ }^{3}$ Department of Ophthalmology, Asan Medical Center, Seoul, Republic of Korea

${ }^{4}$ Department of Gastroenterology, CHA Bundang Medical Center, Seongnam, Republic of Korea

${ }^{5}$ FM Kirby Neurobiology Center, Boston Children's Hospital, Harvard Medical School, Boston, MA, United States

${ }^{6}$ Critical Care Research Group, Nuffield Department of Clinical Neurosciences, Oxford, United Kingdom

${ }^{7}$ Department of Internal Medicine, Gangnam Severance Hospital, Yonsei University College of Medicine, Seoul, Republic of Korea

${ }^{8}$ Department of Pediatrics, Kangnam Sacred Heart Hospital, Hallym University College of Medicine, Seoul, Republic of Korea

${ }^{9}$ Department of Pediatrics, CHA Bundang Medical Center, CHA University School of Medicine, Seongnam, Republic of Korea

${ }^{10}$ Armed Force Medical Command, Republic of Korea Armed Forces, Seongnam, Republic of Korea

these authors contributed equally

\section{Corresponding Author:}

Dong Keon Yon, MD

Armed Force Medical Command

Republic of Korea Armed Forces

81 Saemaeul-ro 177

Seongnam, 463-040

Republic of Korea

Phone: 82269352476

Fax: 825044780201

Email: yonkkang@gmail.com

\section{Abstract}

Background: Evidence regarding the effectiveness of contact tracing of COVID-19 and the related social distancing is limited and inconclusive.

Objective: This study aims to investigate the epidemiological characteristics of SARS-CoV-2 transmission in South Korea and evaluate whether a social distancing campaign is effective in mitigating the spread of COVID-19.

Methods: We used contract tracing data to investigate the epidemic characteristics of SARS-CoV-2 transmission in South Korea and evaluate whether a social distancing campaign was effective in mitigating the spread of COVID-19. We calculated the mortality rate for COVID-19 by infection type (cluster vs noncluster) and tested whether new confirmed COVID-19 trends changed after a social distancing campaign.

Results: There were 2537 patients with confirmed COVID-19 who completed the epidemiologic survey: 1305 (51.4\%) cluster cases and $1232(48.6 \%)$ noncluster cases. The mortality rate was significantly higher in cluster cases linked to medical facilities $(11 / 143,7.70 \%$ vs 5/1232, $0.41 \%$; adjusted percentage difference $7.99 \%$; $95 \%$ CI 5.83 to 10.14$)$ and long-term care facilities (19/221, 8.60\% vs 5/1232, 0.41\%; adjusted percentage difference 7.56\%; 95\% CI 5.66 to 9.47) than in noncluster cases. The change in trends of newly confirmed COVID-19 cases before and after the social distancing campaign was significantly negative in the entire cohort (adjusted trend difference $-2.28 ; 95 \% \mathrm{CI}-3.88$ to -0.68 ) and the cluster infection group (adjusted trend difference $-0.96 ; 95 \%$ CI -1.83 to -0.09 ).

Conclusions: In a nationwide contact tracing study in South Korea, COVID-19 linked to medical and long-term care facilities significantly increased the risk of mortality compared to noncluster COVID-19. A social distancing campaign decreased the spread of COVID-19 in South Korea and differentially affected cluster infections of SARS-CoV-2. 
(JMIR Med Inform 2020;8(8):e20992) doi: 10.2196/20992

\section{KEYWORDS}

COVID-19; contact tracing; coronavirus; South Korea; survey; health data; epidemiology; transmission

\section{Introduction}

The novel coronavirus that emerged in Wuhan, China, termed SARS-CoV-2, has caused a rapidly spreading outbreak of COVID-19 worldwide [1,2]. As of April 7, 2020, there were 1,279,722 human COVID-19 cases and 72,614 deaths worldwide [3], prompting public health interventions that mitigate transmission of the pandemic such as wearing face masks, practicing social distancing, and following home confinement recommendations. As China is a unitary one-party socialist republic with strong governmental control, entire cities in the Wuhan Province were locked down and underwent aggressive measures that brought the epidemic under control $[1,4]$. However, little is known about public health interventions in democratic countries.

The democratic republic of South Korea, one of the geographical neighbors of China, had the second highest number of COVID-19 cases until February 2020 [5]. However, with a well-organized testing program, contact tracing, strict case isolation, and public cooperation that included wearing masks and washing hands, Korea has emerged as a model country with exemplary public health interventions [6]. As of April 11, 2020, COVID-19 cases have dropped sharply, and only 30 new infections have been reported in South Korea since. Further, there have been no new infections in the Daegu Region, which had the highest proportion of COVID-19 cases (65\% of South Korea's total number of cases) [3]. Therefore, epidemiological data and experience regarding the characteristics of SARS-CoV-2 transmission in Korea are valuable to find the right strategies to combat COVID-19.

Based on the experience with the Middle East respiratory syndrome (MERS) outbreak, South Korea has set up a novel monitoring system to collect information and manage patients with COVID-19 and their contacts by using GPD (cell phone location), card transaction logs, closed-circuit television (CCTV), and a history of medical facility use [7]. Using data acquired by this monitoring system, we investigated the epidemiological characteristics of SARS-CoV-2 transmission in South Korea and evaluated whether the social distancing campaign is effective in mitigating the spread of COVID-19.

\section{Methods}

\section{Data Collection}

Data were collected from individuals with laboratory-confirmed SARS-CoV-2 infection who subsequently completed the preliminary epidemiological surveillance conducted by each local government of South Korea (Seoul, Incheon, Sejong, Daegu, Gwangju, Ulsan, Busan, Gyeonggi-do, Gangwon-do, Chungcheongbuk-do [Chungbuk], Chungcheongnam-do [Chungnam], Gyeongsangbuk-do [Gyeongbuk], Gyeongsangnam-do [Gyeongnam], Jeollabuk-do [Jeonbuk], Jeollanam-do [Jeonnam], and Jeju) [8-12] and the Korea Centers for Disease Control and Prevention (KCDC) between January 19, 2020, and April 7, 2020. Epidemiological surveillance data were collected by epidemic intelligence service officers of each local government and the KCDC using the novel monitoring system that uses GPS (cell phone location), card transaction logs, CCTV, and a history medical facilities use. The study protocol was approved by the Institutional Review Board of Sejong University (SJU-HR-E-2020-003) and written informed consent was waived by the ethics commission, owing to the urgent need to collect data.

A cluster infection was defined as a group of similar COVID-19 cases that occurred in the same area during a short time interval. Nonclustered cases were patients with COVID-19 unrelated to any other patients with COVID-19 in time or place [13]. Laboratory confirmation of SARS-CoV-2 infection was defined as a positive result of real-time reverse transcriptase polymerase chain reaction assay of nasal or pharyngeal swabs, in agreement with the World Health Organization (WHO) guideline [14]. Information on age, sex, region of residence, and infection route was obtained for each participant. Death data as of April 7, 2020, were obtained by the KCDC.

\section{Statistical Analysis}

We set January 19, 2020, as the index date (epidemiologic day 1) and April 7, 2020, as epidemiologic day 80. The primary endpoint was the mortality risk among participants with noncluster infection and those with cluster infection. Analysis of covariance was used to calculate the adjusted mean difference and $95 \% \mathrm{CI}$ after adjustment. The following factors were considered potential confounders: age (0-19 years, 20-39 years, 40-59 years, and 60 years or older), sex, diagnosis date, and region of residence (urban [Seoul, Incheon, Sejong, Daegu, Gwangju, Ulsan, and Busan] vs rural [Gyeonggi-do, Gangwon-do, Chungbuk, Chungnam, Gyeongbuk, Gyeongnam, Jeonbuk, Jeonnam, and Jeju]).

Our secondary endpoint was whether a social distancing campaign was effective in mitigating the spread of COVID-19. We divided the population into two distinct periods: before the social distancing campaign (January 19, 2020, to March 22, 2020) and after the social distancing campaign (March 23, 2020, to April 7, 2020). We tested whether trends in newly confirmed COVID-19 cases changed after the social distancing campaign compared with those before the campaign. We implemented interrupted time series analysis to detect a change of slope after the launch of the nationwide social distancing campaign. We introduced the following equation to compare the effect of the campaign, where:

$$
\begin{aligned}
Y_{t}=\alpha_{0} & +\alpha_{1} T+\alpha_{2} \times 1\{T \geq \tilde{T}\}+\alpha_{3}(T-\tilde{T}) \times 1\{T \geq \tilde{T}\} \\
& +\beta_{1} X_{r t}+\beta_{2} X_{a t}+\beta_{3} X_{s t}+\gamma D O W_{t}+e_{t}
\end{aligned}
$$

$\mathrm{Y}_{\mathrm{t}}$ is the newly infected person on day $\mathrm{t}$; $\mathrm{T}$ is the number of days elapsed from the first confirmed infectious case; $\widetilde{\mathrm{T}}$ is the 
breakpoint day with the day when the nationwide social distancing campaign was launched (64); $\alpha_{0}$ is the number of infected patients on the first day of the infection; $\alpha_{1}$ is the slope of novel cases per day before the campaign; $\alpha_{2}$ is the newly infected cases at the start of the campaign compared to $\alpha_{0} ; \alpha_{3}$ is the difference in novel infection rate before and after launching the campaign. Therefore, $\alpha_{1}+\alpha_{3}$ is the trend of the number of daily new infections after the onset of the campaign. $\mathrm{X}_{\mathrm{rt}}, \mathrm{X}_{\mathrm{at}}$, and $\mathrm{X}_{\mathrm{st}}$ are vectors each containing region specificity, age distribution, and gender composition of the patients on day $\mathrm{t}$, and $\beta_{1}, \beta_{2}$, and $\beta_{3}$ are the proportional coefficients of each covariate vector. $\mathrm{DOW}_{\mathrm{t}}$ is the day of the week (eg, Saturday) on day $t, \gamma$ is its coefficient, and $e_{t}$ is an error term.

Network visualization was performed using Gephi version 0.9.2 [15]. The relative positions of nodes and edges were implemented by the Fruchterman-Reingold algorithm [16]. The algorithm would optimally draw the whole layout of the graph to cluster similar nodes and simplify the path of edges to express the transmission routes clearer. Next, we added the "Nooverlap" option to increase visibility further. The dot represented an individual and the line represented an individual tracing result. Larger dots represent clustered infections, where size was proportional to the number of infected individuals. Overseas influx and influx of community-acquired infections (Daegu and two cities in Gyeongbuk [Cheongdo and Gyeongsan]) connected 641 and 229 dots, respectively.

Each categorical value is reported as the number of patients (percentage). Statistical analyses were performed using SPSS version 25.0 (IBM Corp), and $\mathrm{R}$ software version 3.6.2 ( $\mathrm{R}$ Foundation for Statistical Computing). A two-sided $P$ value $<.05$ was considered statistically significant.

\section{Patient and Public Involvement}

No patients were directly involved in designing the research question or conducting the research. No patients were asked to interpret or write up the results. There are no plans to involve patients or relevant patient communities in dissemination at this moment.

\section{Results}

From January 19, 2020, to April 7, 2020, there were 10,046 patients with laboratory-confirmed COVID-19 in South Korea. Among the 10,046 patients, 7509 were excluded for the following reasons: epidemiological investigation was not possible due to community-level outbreaks (Daegu and two cities in Gyeongbuk [Cheongdo and Gyeongsan]; $n=7493$ ) or because the epidemiological investigation was incomplete $(\mathrm{n}=16)$. The final sample size was 2537 (1160 men and 1377 women; Figure 1).

Figure 1. Our study population in each region (number of our study population/number of total patients with confirmed COVID-19). Of 9550 patients with confirmed COVID-19, there were 2134 patients with confirmed COVID-19 who completed the epidemiological surveillance.

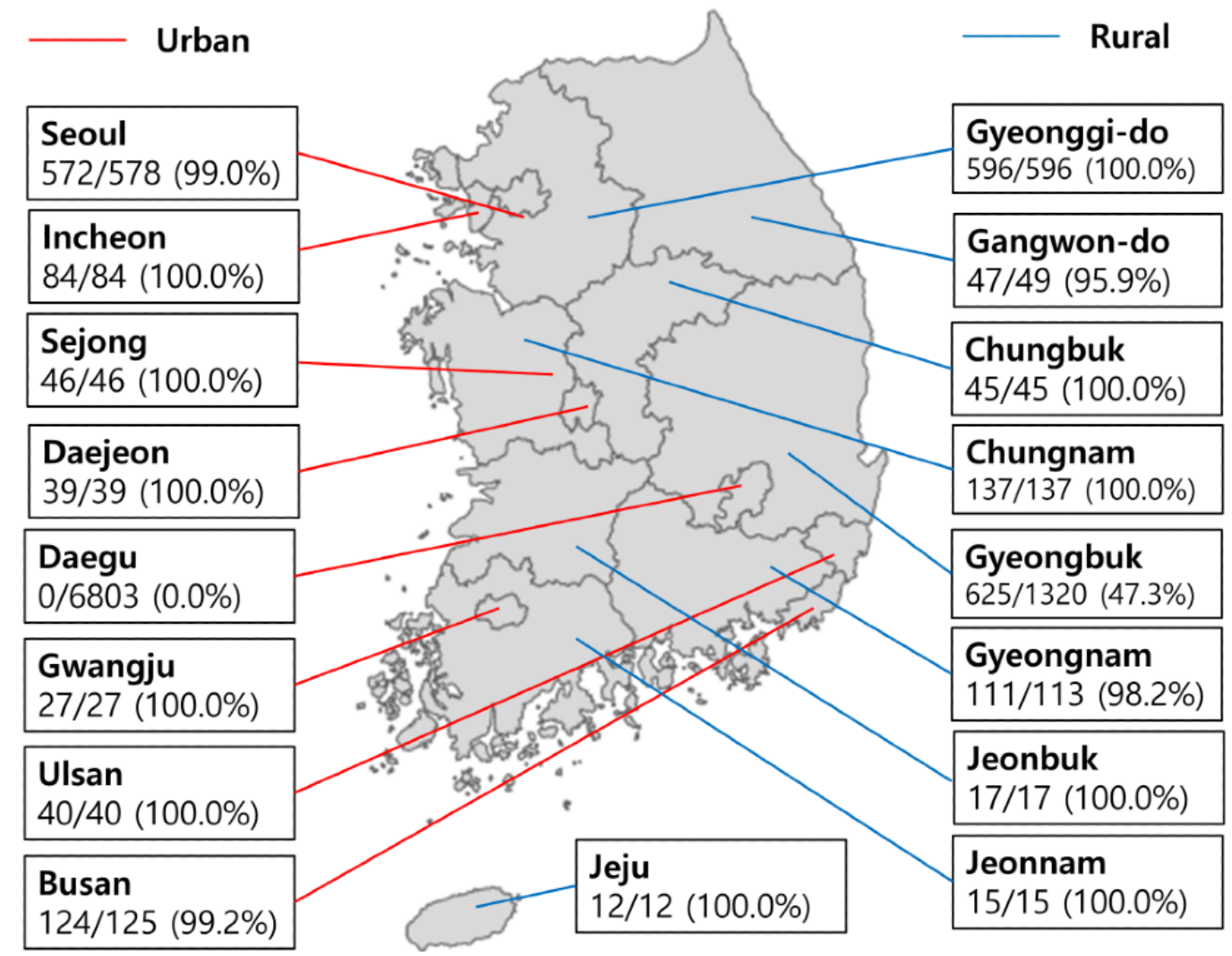

Table 1 shows the demographic characteristics of the participants. There were 1305 cluster cases $(51.4 \%)$ and 1232 noncluster cases $(48.6 \%$; Figure 2$)$. Cluster cases were linked to medical facilities $(n=143,5.6 \%)$, long-term care facilities $(\mathrm{n}=221,8.7 \%)$, religious facilities $(\mathrm{n}=486,19.2 \%)$, and other locations ( $n=455,17.9 \%)$, which included military units, dance studios, karaoke bars, internet cafés, public transport, prisons, and the workplaces of each patient. Noncluster cases were linked 
to the overseas influx $(n=641,25.3 \%)$, influx in cases $(n=362,14.3 \%)$. Figure 3 and Multimedia Appendix 1 community-infection outbreak areas $(n=229,9.0 \%)$, and sporadic show the infection spread network visualization of COVID-19.

Table 1. Demographic characteristics of patients with confirmed COVID-19 in South Korea.

\begin{tabular}{|c|c|c|c|c|c|c|}
\hline \multirow[t]{2}{*}{ Characteristic } & \multirow{2}{*}{$\begin{array}{l}\text { Entire cohort, } \\
\mathrm{n}(\%)\end{array}$} & \multicolumn{4}{|c|}{ Cluster and contact cases, $\mathrm{n}(\%)$} & \multirow{2}{*}{$\begin{array}{l}\text { Noncluster cas- } \\
\mathrm{es}^{\mathrm{a}}, \mathrm{n}(\%)\end{array}$} \\
\hline & & $\begin{array}{l}\text { Linked to medical } \\
\text { facilities }\end{array}$ & $\begin{array}{l}\text { Linked to long-term care } \\
\text { facilities }\end{array}$ & $\begin{array}{l}\text { Linked to religious fa- } \\
\text { cilities }\end{array}$ & Others $^{b}$ & \\
\hline Patients & $2537(100)$ & $143(5.6)$ & $221(8.7)$ & $486(19.2)$ & 455 (17.9) & $1232(48.6)$ \\
\hline \multicolumn{7}{|l|}{ Age (years) } \\
\hline $0-19$ & $151(6.0)$ & $3(2.1)$ & $2(0.9)$ & $33(6.8)$ & $35(7.7)$ & $78(6.3)$ \\
\hline $20-39$ & $974(38.4)$ & $28(19.6)$ & $15(6.8)$ & $196(40.3)$ & $123(27.0)$ & $612(49.7)$ \\
\hline $40-59$ & $805(31.7)$ & $44(30.8)$ & 39 (17.6) & $162(33.3)$ & $240(52.7)$ & $320(26.0)$ \\
\hline$\geq 60$ & $607(23.9)$ & 68 (47.6) & $165(74.7)$ & 95 (19.5) & $57(12.5)$ & $222(18.0)$ \\
\hline \multicolumn{7}{|l|}{ Sex } \\
\hline Male & $1160(45.7)$ & $49(34.3)$ & $68(30.8)$ & $228(46.9)$ & $176(38.7)$ & $639(51.9)$ \\
\hline Female & $1377(54.3)$ & $94(65.7)$ & $153(69.2)$ & $258(53.1)$ & $279(61.3)$ & $593(48.1)$ \\
\hline \multicolumn{7}{|c|}{ Region of residence } \\
\hline Urban & $934(36.8)$ & $25(17.5)$ & $8(3.6)$ & $146(30.0)$ & $210(46.2)$ & $545(44.2)$ \\
\hline Rural & $1603(63.2)$ & $118(82.5)$ & $213(96.4)$ & $340(70.0)$ & $245(53.8)$ & $687(55.8)$ \\
\hline \multicolumn{7}{|l|}{ Died } \\
\hline No & $2500(98.5)$ & $132(92.3)$ & $202(91.4)$ & $485(99.8)$ & $454(99.8)$ & 1227 (99.6) \\
\hline Yes & $37(1.5)$ & $11(7.7)$ & $19(8.6)$ & $1(0.2)$ & $1(0.2)$ & $5(0.4)$ \\
\hline
\end{tabular}

${ }^{\mathrm{a}}$ Noncluster cases were linked to overseas influx (641/2537, 25.3\%), influx for community-infection outbreak areas (229/2537, 9.0\%), and sporadic cases $(362 / 2537,14.3 \%)$.

${ }^{\mathrm{b}}$ Other facilities included military units, dance studios, karaoke, internet cafés, public transport, prisons, and workplaces of each patient.

Figure 2. Number of infections based on infection type (cluster and contact cases vs noncluster cases) in South Korea from January 19, 2020, to April 7, 2020.

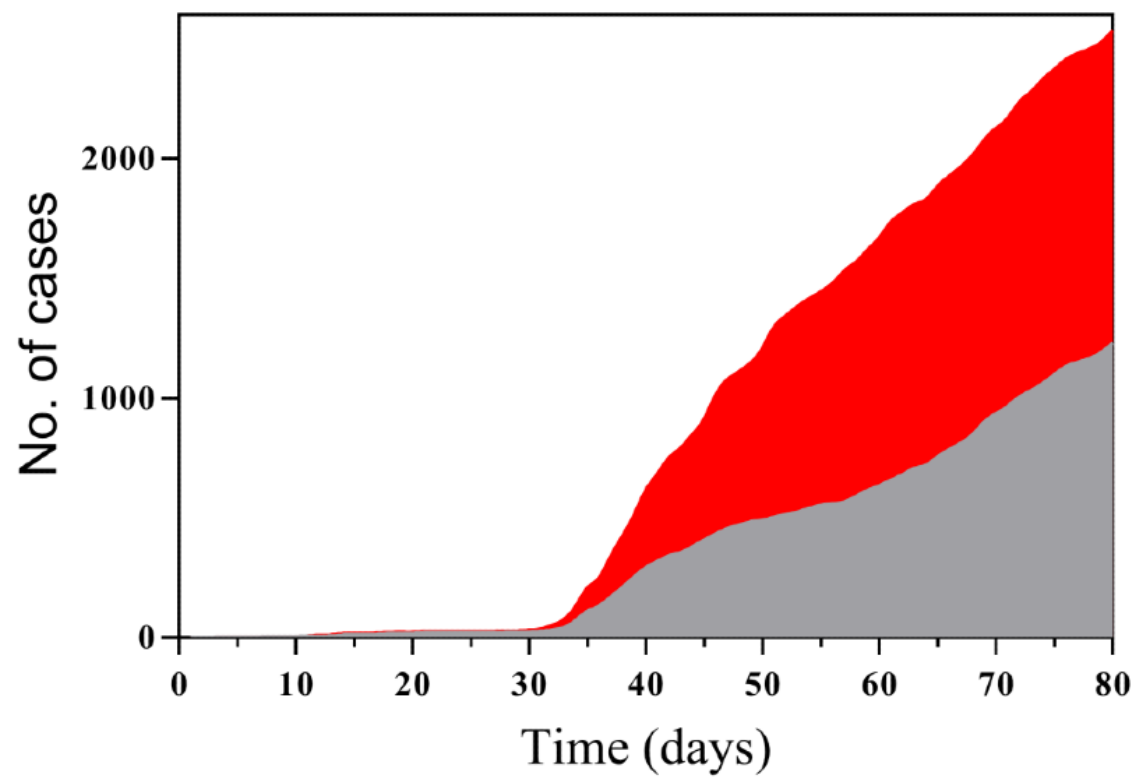


Figure 3. Infection spread network visualization of COVID-19 in South Korea from January 19, 2020, to April 7, 2020. Each dot represents an individual, and each line represents an individual's tracing results. Overseas influx and influx of community-acquired infections (Daegu and two cities in Gyeongbuk [Cheongdo and Gyeongsan]) are shown by 641 and 229 connected dots, respectively. CA: community-acquired.

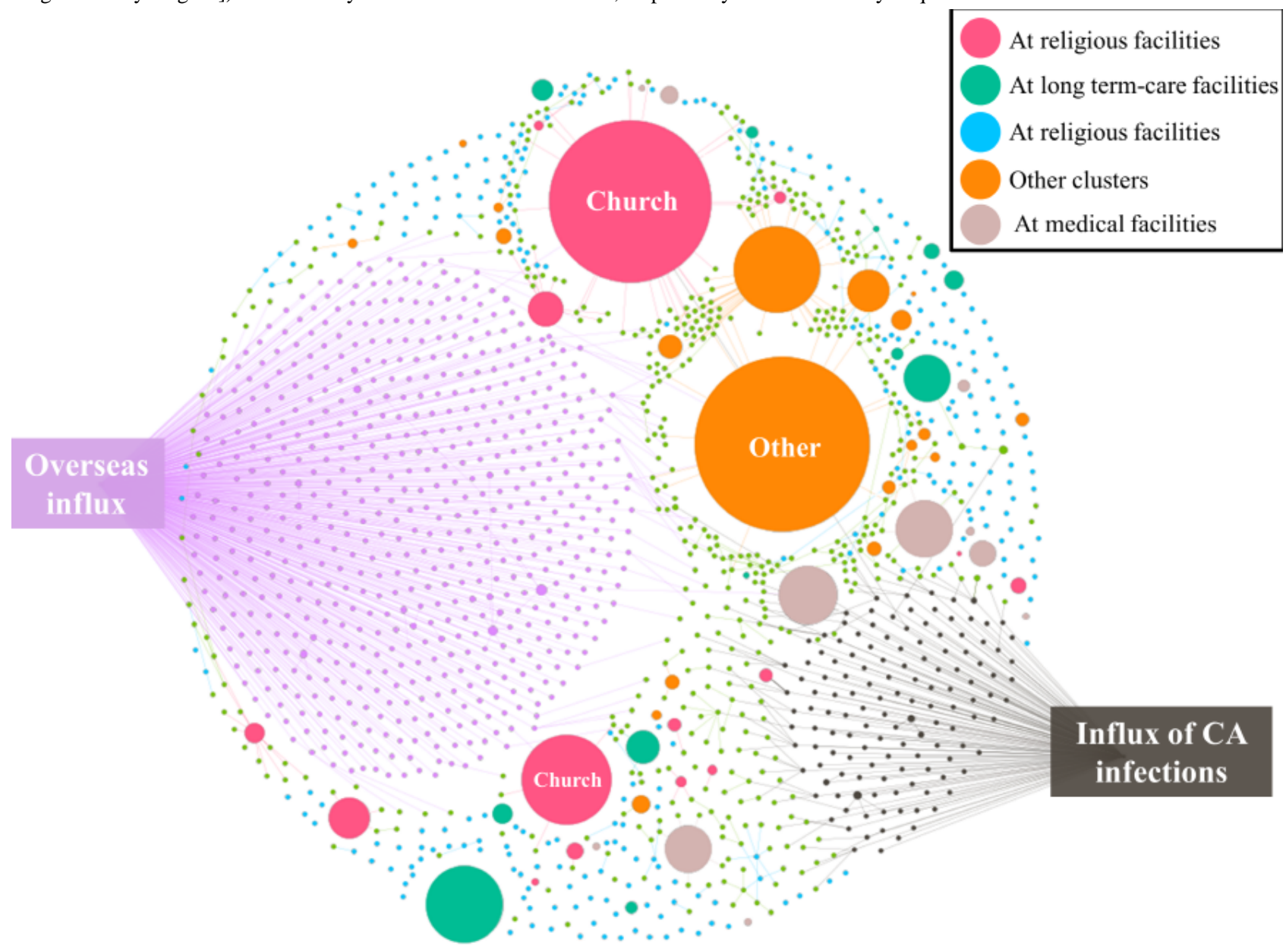

Table 2 indicates the mortality rate of COVID-19 according to the infection route. The multivariable regression analysis showed that the mortality was significantly higher in cluster cases linked to medical facilities $(11 / 143,7.70 \%$ vs $5 / 1232,0.41 \%$; adjusted percentage difference $7.99 \%$; 95\% CI 5.83 to 10.14$)$ and long-term care facilities $(19 / 221,8.60 \%$ vs $5 / 1232,0.41 \%$; adjusted percentage difference $7.56 \%$; $95 \%$ CI 5.66 to 9.47 ) than in noncluster cases.

Table 2. Mortality rate for COVID-19 according to the infection route in South Korea $(\mathrm{n}=2134){ }^{\mathrm{a}}$

\begin{tabular}{llll}
\hline Cases & Mortality percentage $(95 \% \mathrm{CI})$ & Adjusted difference $(95 \% \mathrm{CI})$ & $P$ value \\
\hline $\begin{array}{l}\text { Noncluster cases } \\
\text { Cluster and their contact cases }\end{array}$ & $0.41(-0.25$ to 1.06$)$ & Reference & \\
$\quad$ Linked to medical facilities & $7.70(5.78$ to 9.61$)$ & $7.99(5.83$ to 10.14$)$ & $7.56(5.66$ to 9.47$)$ \\
$\quad$ Linked to long-term care facilities & $8.60(7.06$ to 10.14$)$ & $-0.14(-1.40$ to 1.13$)$ & $<.001$ \\
$\quad$ Linked to religious facilities & $0.21(-0.83$ to 1.24$)$ & $-0.14(-1.42$ to 1.15$)$ & .88 \\
$\quad 0.22(-0.85$ to 1.29$)$ & & .88 \\
\hline
\end{tabular}

${ }^{\mathrm{a}}$ Risk factors were adjusted by age (0-19 years, 20-39 years, $40-59$ years, and 60 years or older), sex, diagnosis date, and region of residence (urban [Seoul, Incheon, Sejong, Daegu, Gwangju, Ulsan, and Busan] vs rural [Gyeonggi-do, Gangwon-do, Chungbuk, Chungnam, Gyeongbuk, Gyeongnam, Jeonbuk, Jeonnam, and Jeju]).

Table 3 and Figure 4 show the trend in newly confirmed COVID-19 cases after the social distancing campaign by infection route. The trend was significantly negative in the overall population (adjusted trend difference -2.28 ; 95\% CI -3.88 to -0.68 ) and the cluster infection group (adjusted trend difference, -0.96 ; $95 \% \mathrm{CI}-1.83$ to -0.09 ). 
Table 3. New confirmed COVID-19 cases trends before and after a social distancing campaign in South Korea. ${ }^{\mathrm{a}}$

\begin{tabular}{|c|c|c|c|c|}
\hline Groups & $\begin{array}{l}\text { Trend before the social distancing } \\
\text { campaign }(95 \% \text { CI })\end{array}$ & $\begin{array}{l}\text { Trend after the social distancing } \\
\text { campaign }(95 \% \mathrm{CI})\end{array}$ & Trend difference $(95 \% \mathrm{CI})$ & $P$ value \\
\hline Overall & $1.11(0.62$ to 1.59$)$ & $-1.18(-2.70$ to 0.34$)$ & $-2.28(-3.88$ to -0.68$)$ & .005 \\
\hline Cluster & $0.43(-0.10$ to 0.96$)$ & $-0.53(-1.22$ to 0.17$)$ & $-0.96(-1.83$ to -0.09$)$ & .03 \\
\hline Noncluster & $0.35(0.16$ to 0.54$)$ & $-0.34(-1.34$ to 0.67$)$ & $-0.69(-1.71$ to 0.33$)$ & .19 \\
\hline
\end{tabular}

${ }^{\mathrm{a}}$ Risk factors were adjusted by age, sex, and region of residence.

Figure 4. Number of new confirmed COVID-19 cases over the study period. The dashed vertical line at March 22,2020 , indicates the launch of the social distancing campaign. The solid red (before the social distancing campaign) and blue (after the social distancing campaign) lines represent the linear trends of new confirmed COVID-19 cases. Shaded areas represent 95\% CIs for the linear trends.
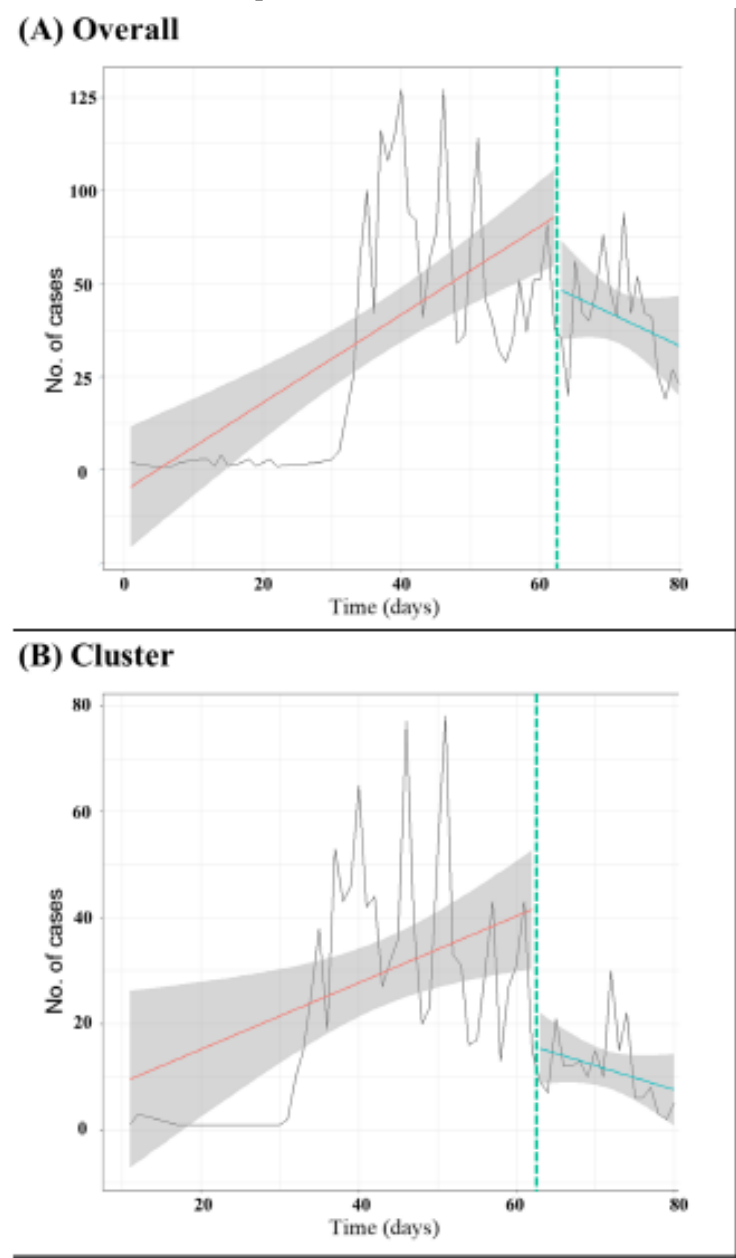

(C) Noncluster

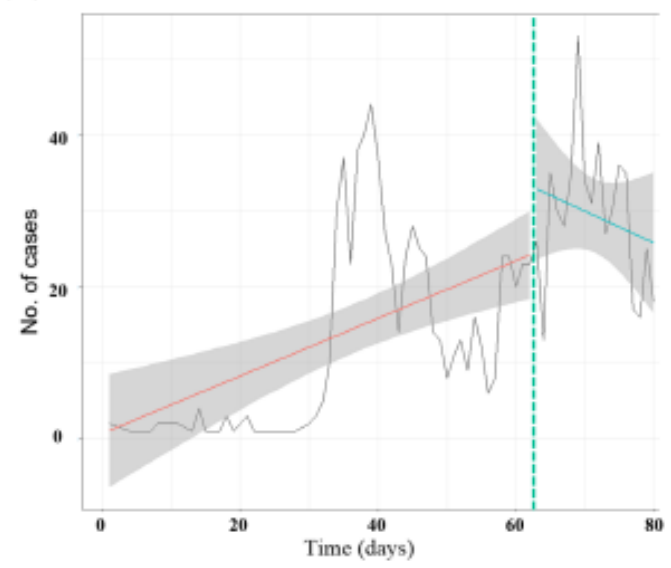




\section{Discussion}

\section{Principal Findings}

To our knowledge, this is the first study to investigate the results of nationwide contact tracing of patients with COVID-19 and examine whether a social distancing campaign is effective in mitigating the spread of COVID-19. Cases of cluster infection and their contacts, which accounted for $51.4 \%$ (1305/2537) of the cases in this study, were linked to medical facilities, long-term care facilities, religious facilities, and other locations (military units, dance studios, karaoke bars, internet cafés, public transport, prisons, and workplaces of each patient). Moreover, COVID-19 linked to medical and long-term care facilities significantly increased the risk of mortality compared to noncluster COVID-19. Our study also showed that the social distancing campaign decreased the spread of COVID-19 in South Korea and differentially affected cluster infections of SARS-CoV-2. Therefore, strategies for the prevention of cluster infection of SARS-CoV-2 should be personalized and comprehensive, and multidisciplinary strategies to prevent COVID-19 should be developed. In particular, special attention should be paid to prevent cluster infections of SARS-CoV-2, especially in medical and long-term care facilities.

The pandemic spread of COVID-19 is exponentially escalating $[17,18]$. Cases of COVID-19 grew by several thousand each day in China in late January and early February, and took 2-3 days to double from 1000 to 2000 outside of China [1,17,19]. The velocity of the SARS-CoV-2 spread is substantially higher than that of the coronaviruses causing severe acute respiratory syndrome (SARS) and MERS (48 days for the first 1000 people to be diagnosed with COVID-19 compared to 130 days for SARS and 903 days for MERS) [2,20]. Aside from the characteristics of the virus itself, we investigated the epidemiological aspects of SARS-CoV-2 transmission in South Korea using contact tracing of confirmed cases and analyzed factors that may accelerate infection and death. We found three significant factors. First, cluster cases accounted for the highest portion of SARS-CoV-2-positive cases; second, overseas influx was significantly involved; and third, the majority of cases were confined to a specific area (Daegu Region).

An in-depth analysis of clustered cases revealed that a higher proportion of confirmed COVID-19 cases were related to religious, long-term care, and medical facilities. Cases from medical and long-term care facilities had a high mortality rate $(11 / 143,7.70 \%$ and $19 / 221,8.60 \%$, respectively) due to a higher proportion of vulnerable people including older adults and patients who are chronically ill present among these cases. These facilities are typically crowded with people in enclosed rooms, which create favorable conditions for transmission of respiratory diseases [21,22]. South Korea has the highest number of nursing hospitals (long-term care hospitals: 27.35 per 1000 people aged $\geq 65$ years) and the longest average length of hospital stay (average 18.5 days) of all Organisation for Economic Co-operation and Development countries [23]. Therefore, more care with strict regulation and quarantine programs should be applied to these kinds of facilities to avoid massive clusters of infection.
The enforced social distancing campaign was introduced by the Korean government on March 22, 2020. Our data support the enforced social distancing campaign as a highly effective method for preventing clustered infections. Our analyses demonstrated a significant reduction in clustered SARS-CoV-2 infections (adjusted trend difference $-0.96 ; 95 \% \mathrm{CI}-1.83$ to -0.09 ) after the launch of the nationwide campaign. Since SARS-CoV-2 is transmitted via respiratory droplets [24,25], the purpose of the campaign was to keep a minimum distance to avoid transmission while maintaining personal hygiene. A droplet will fall under gravity or evaporate within 2 meters of the infected individual; therefore, staying 2 meters, or approximately three steps, away from other individuals will theoretically prevent droplet-induced transmission [26]. In addition to keeping personal distance, enforced social distancing includes following basic guidelines at work, religious facilities, sports and entertainment facilities, and other high-risk facilities, such as refraining from going outdoors when experiencing respiratory symptoms; having online gatherings instead of personal meetings; keeping a distance and avoiding talking when you eat; using personal belongings instead of sharing items; and keeping hand sanitizer available at entrances of buildings, elevators, and stairways.

It is interesting to note that the overseas influx had a significant role in the spread of the virus in South Korea. Recently, many countries have imposed government-issued international travel restrictions [27]. Although restricting travel may be useful in the early stage of the outbreak, it may be less successful once the outbreak is widespread [28]. Therefore, banning visitors from China or other COVID-19 high-risk countries to reduce the risk of reintroduction of the virus might be effective in countries that are at the early stage of the COVID-19 outbreak. However, for countries with a high incidence of COVID-19, an alternative strategy must be applied to mitigate SARS-CoV-2 transmission.

\section{Policy Implications}

As the nature of COVID-19 is subclinical in some individuals, isolating early detected confirmed cases before transmission can occur is difficult [29]. Therefore, substantial effort should be made to prevent the virus from spreading by developing effective public health policy. First, public health policy should advise against social gatherings such as mass conferences, sporting events, musical concerts, and religious meetings. Instead, working remotely, online conferences, and online religious services should be encouraged. Second, strict screening and quarantine should be applied to those entering or leaving a region. Routine screening for SARS-CoV-2 and self-isolation should be required of visitors from areas of high incidence of COVID-19. Third, individuals should be advised against travel to regions of high COVID-19 incidence. Surveys of medical or long-term care facility visitors should be routinely conducted to screen for a history of visits to areas of high COVID-19 incidence. In addition, testing for COVID-19 should be required for patients and residents as well as staff and visitors in medical and long-term care facilities to prevent the introduction of COVID-19 in those facilities. 


\section{Strengths and Limitations}

First, as previously mentioned, one of the strengths of our study is that novel individual contact tracing data acquired by the KCDC and each local government in South Korea was used. By tracing individual data, we could categorize the source and characteristics of the transmission. Additionally, most other countries have not performed epidemiological surveys that include contact tracing; South Korea is thus far the only country to conduct epidemiological surveys with contact tracing. Therefore, we were able to identify the spread dynamics of COVID-19. Second, our study has a clear time point when a nationwide social distancing campaign was launched. Therefore, we could compare the trends of transmission before and after the campaign and evaluate the effectiveness of the public health intervention. Nonetheless, our study has some limitations. First, our data did not contain clinical information because we could not link hospital data to the epidemiological survey expeditiously. Second, we are still developing epidemiological surveys that include information on socioeconomic status (personal occupation and income) and time to development of COVID-19-related symptoms; hence, we were unable to analyze the time to symptom onset or socioeconomic status. Third, although the WHO stated that contact tracing includes the process of identifying, assessing, and managing people who have been exposed to a disease to prevent onward transmission [30], we only had tracing from confirmed cases; tracing for exposure remains for future study. Finally, epidemiological surveillance was not possible in some regions due to community-level outbreaks (Daegu and two cities in Gyeongbuk [Cheongdo and Gyeongsan]). Therefore, data from those regions were excluded.

\section{Conclusion}

In this study, we investigated the nationwide contact tracing results of patients with COVID-19 and whether the social distancing campaign was effective in mitigating the spread of COVID-19. COVID-19 linked to medical and long-term care facilities significantly increased the risk of mortality compared with noncluster COVID-19. Moreover, our study shows that the social distancing campaign decreased the spread of COVID-19 in South Korea and differentially affected cluster infections of SARS-CoV-2. Therefore, our data may support driving public health policies in other countries and help normalize and restore social activities while minimizing the risk of transmission. Further cooperative global epidemic studies and updates are warranted to drive the best policy to control the transmission of SARS-CoV-2.

\section{Acknowledgments}

This work was supported by the Institute of Information and Communications Technology Planning \& Evaluation grant funded by the Korea government (MSIT); No.2020-0-00512, Data Refinement and Improvement through Data Quality Evaluation. The funders had no role in the study design, data collection, data analysis, data interpretation, or writing of the report.

\section{Authors' Contributions}

DKY had full access to all of the data in the study and took responsibility for the integrity of the data and the accuracy of the data analysis. All authors approved the final version before submission. The study concept and design was done by SWL, WTY, and DKY. Acquisition, analysis, or interpretation of data was done by SWL, WTY, and DKY. Drafting of the manuscript was done by JMY and DKY. Critical revision of the manuscript for important intellectual content was done by Y-SC, IKY, HYK, DM, DO, EKH, MYH, and DKY. Statistical analysis was done by SWL, Y-SC, and DKY. Study supervision was done by DKY. DKY is guarantor. The corresponding author attests that all listed authors meet authorship criteria and that no others meeting the criteria have been omitted.

\section{Conflicts of Interest}

None declared.

\section{Multimedia Appendix 1}

The dynamic infection spread network video of the COVID-19 in South Korea. The bottom bar represents the elapsed day after the first infection has occurred. The video includes the first 80 days of spread. Each line represents the spread occurrence between persons, and each dot represents the infected individual. Larger dots represent clustered infections, with dynamically increasing size, which means the number of infections in that cluster as time proceeds.

[MP4 File (MP4 Video), 6720 KB-Multimedia Appendix 1]

\section{References}

1. Pan A, Liu L, Wang C, Guo H, Hao X, Wang Q, et al. Association of public health interventions with the epidemiology of the COVID-19 outbreak in Wuhan, China. JAMA 2020 Apr 10 [FREE Full text] [doi: 10.1001/jama.2020.6130] [Medline: 32275295]

2. Park SE. Epidemiology, virology, and clinical features of severe acute respiratory syndrome -coronavirus-2 (SARS-CoV-2; Coronavirus Disease-19). Clin Exp Pediatr 2020 Apr;63(4):119-124 [FREE Full text] [doi: 10.3345/cep.2020.00493] [Medline: $\underline{\text { 32252141] }}$ 
3. Coronavirus disease 2019 (COVID-19) situation report - 78. World Health Organization. 2020 Apr 07. URL: https://www. who.int/docs/default-source/coronaviruse/situation-reports/20200407-sitrep-78-covid-19.pdf?sfvrsn=bc43e1b 2

4. Choi S, Kim HW, Kang J, Kim DH, Cho EY. Epidemiology and clinical features of coronavirus disease 2019 in children. Clin Exp Pediatr 2020 Apr;63(4):125-132 [FREE Full text] [doi: 10.3345/cep.2020.00535] [Medline: 32252139]

5. Korean Society of Infectious Diseases, Korean Society of Pediatric Infectious Diseases, Korean Society of Epidemiology, Korean Society for Antimicrobial Therapy, Korean Society for Healthcare-associated Infection Control and Prevention, Korea Centers for Disease Control and Prevention. Report on the epidemiological features of coronavirus disease 2019 (COVID-19) outbreak in the Republic of Korea from January 19 to March 2, 2020. J Korean Med Sci 2020 Mar 16;35(10):e112 [FREE Full text] [doi: 10.3346/jkms.2020.35.e112] [Medline: 32174069]

6. Normile D. Coronavirus cases have dropped sharply in South Korea. What's the secret to its success? Science 2020 Mar 18. [doi: $10.1126 /$ science.abb7566]

7. COVID-19 National Emergency Response Center, Epidemiology \& Case Management Team, Korea Centers for Disease Control \& Prevention. Contact transmission of COVID-19 in South Korea: novel investigation techniques for tracing contacts. Osong Public Health Res Perspect 2020 Feb;11(1):60-63 [FREE Full text] [doi: 10.24171/j.phrp.2020.11.1.09] [Medline: 32149043]

8. Lee SW, Yon DK, James CC, Lee S, Koh HY, Sheen YH, et al. Short-term effects of multiple outdoor environmental factors on risk of asthma exacerbations: age-stratified time-series analysis. J Allergy Clin Immunol 2019

Dec;144(6):1542-1550.e1. [doi: 10.1016/j.jaci.2019.08.037] [Medline: 31536730]

9. Koh HY, Kim TH, Sheen YH, Lee SW, An J, Kim MA, et al. Serum heavy metal levels are associated with asthma, allergic rhinitis, atopic dermatitis, allergic multimorbidity, and airflow obstruction. J Allergy Clin Immunol Pract 2019;7(8):2912-2915.e2. [doi: 10.1016/j.jaip.2019.05.015] [Medline: 31129074]

10. Ha J, Lee SW, Yon DK. Ten-Year trends and prevalence of asthma, allergic rhinitis, and atopic dermatitis among the Korean population, 2008-2017. Clin Exp Pediatr 2020 Jul;63(7):278-283 [FREE Full text] [doi: 10.3345/cep.2019.01291] [Medline: 32023407]

11. Woo A, Lee SW, Koh HY, Kim MA, Han MY, Yon DK. Incidence of cancer after asthma development: 2 independent population-based cohort studies. J Allergy Clin Immunol 2020 May 15. [doi: 10.1016/j.jaci.2020.04.041] [Medline: 32417133]

12. Kong SG. Current use of safety restraint systems and front seats in Korean children based on the 2008-2015 Korea National Health and Nutrition Examination Survey. Korean J Pediatr 2018 Dec;61(12):381-386 [FREE Full text] [doi: 10.3345/kjp.2018.06604] [Medline: 30304902]

13. Lee C, Tsai H, Kunin CM, Lee SS, Wu K, Chen Y. Emergence of sporadic non-clustered cases of hospital-associated listeriosis among immunocompromised adults in southern Taiwan from 1992 to 2013: effect of precipitating immunosuppressive agents. BMC Infect Dis 2014 Mar 19;14:145 [FREE Full text] [doi: 10.1186/1471-2334-14-145] [Medline: 24641498]

14. Grasselli G, Zangrillo A, Zanella A, Antonelli M, Cabrini L, Castelli A, COVID-19 Lombardy ICU Network, et al. Baseline characteristics and outcomes of 1591 patients infected with SARS-CoV-2 admitted to ICUs of the Lombardy Region, Italy. JAMA 2020 Apr 06 [FREE Full text] [doi: 10.1001/jama.2020.5394] [Medline: 32250385]

15. Gephi. URL: https://gephi.org/

16. Fruchterman TMJ, Reingold EM. Graph drawing by force-directed placement. Softw: Pract Exper 1991 Nov;21(11):1129-1164. [doi: 10.1002/spe.4380211102]

17. Guan W, Ni Z, Hu Y, Liang W, Ou C, He J, China Medical Treatment Expert Group for Covid-19. Clinical characteristics of coronavirus disease 2019 in China. N Engl J Med 2020 Apr 30;382(18):1708-1720 [FREE Full text] [doi: 10.1056/NEJMoa2002032] [Medline: 32109013 ]

18. Shah S, Meenakshisundaram R, Senthilkumaran S, Thirumalaikolundusubramanian P. COVID-19 in children: reasons for uneventful clinical course. Clin Exp Pediatr 2020 Jul;63(7):237-238 [FREE Full text] [doi: 10.3345/cep.2020.00801] [Medline: 32664708]

19. Lee K, Rhim J, Kang J. Immunopathogenesis of COVID-19 and early immunomodulators. Clin Exp Pediatr 2020 Jul;63(7):239-250 [FREE Full text] [doi: 10.3345/cep.2020.00759] [Medline: $\underline{32664709}$ ]

20. Callaway E, Cyranoski D, Mallapaty S, Stoye E, Tollefson J. The coronavirus pandemic in five powerful charts. Nature 2020 Mar;579(7800):482-483. [doi: 10.1038/d41586-020-00758-2] [Medline: 32203366]

21. McMichael TM, Currie DW, Clark S, Pogosjans S, Kay M, Schwartz NG, Public Health-Seattle and King County, EvergreenHealth, and CDC COVID-19 Investigation Team. Epidemiology of Covid-19 in a long-term care facility in King County, Washington. N Engl J Med 2020 May 21;382(21):2005-2011 [FREE Full text] [doi: 10.1056/NEJMoa2005412] [Medline: $\underline{32220208]}$

22. Gudbjartsson DF, Helgason A, Jonsson H, Magnusson OT, Melsted P, Norddahl GL, et al. Spread of SARS-CoV-2 in the Icelandic population. N Engl J Med 2020 Jun 11;382(24):2302-2315 [FREE Full text] [doi: 10.1056/NEJMoa2006100] [Medline: $\underline{32289214]}$

23. OECD health statistics 2014 - frequently requested data. OECD. URL: https://www.oecd.org/els/health-systems/ oecd-health-statistics-2014-frequently-requested-data.htm 
24. Chan J, Yuan S, Kok K, To K, Chu H, Yang J, et al. A familial cluster of pneumonia associated with the 2019 novel coronavirus indicating person-to-person transmission: a study of a family cluster. Lancet 2020 Feb;395(10223):514-523. [doi: 10.1016/s0140-6736(20)30154-9]

25. Anfinrud P, Stadnytskyi V, Bax CE, Bax A. Visualizing speech-generated oral fluid droplets with laser light scattering. N Engl J Med 2020 May 21;382(21):2061-2063 [FREE Full text] [doi: 10.1056/NEJMc2007800] [Medline: 32294341]

26. Xie X, Li Y, Chwang ATY, Ho PL, Seto WH. How far droplets can move in indoor environments--revisiting the Wells evaporation-falling curve. Indoor Air 2007 Jun;17(3):211-225. [doi: 10.1111/j.1600-0668.2007.00469.x] [Medline: 17542834]

27. Chinazzi M, Davis JT, Ajelli M, Gioannini C, Litvinova M, Merler S, et al. The effect of travel restrictions on the spread of the 2019 novel coronavirus (COVID-19) outbreak. Science 2020 Apr 24;368(6489):395-400 [FREE Full text] [doi: 10.1126/science.aba9757] [Medline: 32144116 ]

28. Kraemer MUG, Yang C, Gutierrez B, Wu C, Klein B, Pigott DM, Open COVID-19 Data Working Group, et al. The effect of human mobility and control measures on the COVID-19 epidemic in China. Science 2020 May 01;368(6490):493-497 [FREE Full text] [doi: 10.1126/science.abb4218] [Medline: 32213647]

29. Li Q, Guan X, Wu P, Wang X, Zhou L, Tong Y, et al. Early transmission dynamics in Wuhan, China, of novel coronavirus-infected pneumonia. N Engl J Med 2020 Mar 26;382(13):1199-1207. [doi: 10.1056/nejmoa2001316]

30. Ethical considerations to guide the use of digital proximity tracking technologies for COVID-19 contact tracing. World Health Organization. 2020 May 28. URL: https://www.who.int/publications/i/item/

WHO-2019-nCoV-Ethics Contact tracing apps-2020.1

\author{
Abbreviations \\ CCTV: closed-circuit television \\ KCDC: Korea Centers for Disease Control and Prevention \\ MERS: Middle East respiratory syndrome \\ SARS: severe acute respiratory syndrome \\ WHO: World Health Organization
}

\author{
Edited by G Eysenbach; submitted 03.06.20; peer-reviewed by A Ahmed, A Alfadl, P Akande, S Olowookere; comments to author \\ 22.06.20; revised version received 04.07.20; accepted 24.07.20; published 25.08.20 \\ Please cite as: \\ Lee SW, Yuh WT, Yang JM, Cho YS, Yoo IK, Koh HY, Marshall D, Oh D, Ha EK, Han MY, Yon DK \\ Nationwide Results of COVID-19 Contact Tracing in South Korea: Individual Participant Data From an Epidemiological Survey \\ JMIR Med Inform 2020;8(8):e20992 \\ URL: http://medinform.jmir.org/2020/8/e20992/ \\ doi: $\underline{10.2196 / 20992}$ \\ PMID: 32784189
}

(CSeung Won Lee, Woon Tak Yuh, Jee Myung Yang, Yoon-Sik Cho, In Kyung Yoo, Hyun Yong Koh, Dominic Marshall, Donghwan Oh, Eun Kyo Ha, Man Yong Han, Dong Keon Yon. Originally published in JMIR Medical Informatics (http://medinform.jmir.org), 25.08.2020. This is an open-access article distributed under the terms of the Creative Commons Attribution License (https://creativecommons.org/licenses/by/4.0/), which permits unrestricted use, distribution, and reproduction in any medium, provided the original work, first published in JMIR Medical Informatics, is properly cited. The complete bibliographic information, a link to the original publication on http://medinform.jmir.org/, as well as this copyright and license information must be included. 